\title{
OS BENEFÍCIOS DA APLICAÇÃO DA CONCILIAÇÃO A FAZENDA PÚBLICA
}

Larissa Camargo Martins Previato ${ }^{1}$

PREVIATO, L. C. M. Os benefícios da aplicação da conciliação a fazenda pública. Rev. Ciênc. Juríd. Soc. UNIPAR. Umuarama. v. 17, n. 1, p. 105-121, jan./jun. 2014.

RESUMO: O estudo demonstra, mediante pesquisas realizadas pelo Conselho Nacional de Justiça que, atualmente, a Fazenda Pública é uma das maiores litigantes do Poder Judiciário e na busca de se reduzir estes processos de forma célere e eficaz para as partes enumera quais seriam os benefícios da aplicação da conciliação nestas causas. Assim, apresenta uma análise dos meios alternativos de solução dos conflitos, especialmente da conciliação, destacando, em seguida, os principais aspectos da Administração Pública para se poder compreender o conceito de Fazenda Pública. Por fim, verifica-se que a aplicação da conciliação é benéfica para todas as partes, que respeita o Princípio da Indisponibilidade do Interesse Público, pois, segundo o Supremo Tribunal Federal, este Princípio, embora seja considerado um dos pilares de todo direito administrativo, pode ter sua aplicação amenizada, bem como que os Princípios da Legalidade, Celeridade e Economia Processual também são respeitados e cumpridos.

PALAVRAS-CHAVE: Fazenda Pública; Conciliação; Interesse Público.

\section{INTRODUÇÃO}

A Fazenda Pública, hodiernamente, segundo dados de pesquisas realizadas pelo Conselho Nacional de Justiça, é uma das maiores litigantes do Poder Judiciário, dessa forma há a necessidade de se encontrar meios de solucionar estes conflitos de forma célere e eficaz para as partes, bem como de reduzir o número de processos para facilitar o bom funcionamento do judiciário.

Visando a buscar quais seriam os meios eficazes que poderiam ser aplicados para se solucionar estas demandas, inicialmente conceituam-se os meios alternativos de solução dos conflitos, destacando-se a conciliação, pois esta vem sendo muito incentivada e difundida pelos operadores do direito.

Para bem definir o conceito de Fazenda Pública o estudo traz algumas

DOI: https://doi.org/10.25110/rcjs.v17i1.2014.5357

${ }^{1}$ Advogada do Município de Umuarama-PR. Especialista em Direito Tributário, Universidade Anhanguera-Uniderp. Especialisa em Processo Civil pela Universidade Paranaense - UNIPAR. E-mail: laralcm@hotmail.com 
considerações acerca da Administração Pública em geral, sua divisão em administração direta e indireta, ressaltando-se o Princípio da Indisponibilidade do Interesse Público, um dos pilares de todo Direito Administrativo, levando em consideração que o Supremo Tribunal Federal, no julgamento do Recurso Extraordinário n. 253.885/MG, entendeu que é possível sua amenização para melhor atender os interesses da coletividade.

Num segundo momento, visando a demonstrar como a conciliação esta sendo incentivada, analisam-se alguns aspectos $\left(\operatorname{artigos} 2^{\circ}\right.$ e $8^{\circ}$ ) da Lei $n$. 12.153/09 dos Juizados Especiais da Fazenda Pública, que instituiu, a partir de 2.009, a possibilidade de realização da conciliação nas causas em que a Fazenda Pública for parte, desde que a causa seja de até 60 salários mínimos e haja lei do respectivo ente federativo autorizando-a. Ainda, traz algumas considerações acerca da Lei n. 10.259/2.001 dos Juizados Especiais Federais e da Lei n. 1.790/2.008 do Município de Palmas, Estado do Paraná, que já autorizavam a prática da conciliação antes do ano de 2.009 .

$\mathrm{Na}$ sequência, o estudo busca verificar quais seriam os benéficos gerados para as partes caso a conciliação fosse aplicada de forma mais ampla em todos os casos em que a Fazenda Pública figure.

Por fim, também se analisa-se ao aplicar a conciliação em todas essas causas os Princípios da Indisponibilidade do Interesse Público, da Legalidade, da Economia Processual e da Celeridade estarão sendo cumpridos e respeitados.

\section{A CONCILIAÇÃO COMO MEIO ALTERNATIVO DE SOLUÇÃO DOS CONFLITOS}

A vida em sociedade propicia, de forma natural, a existência de conflitos de interesses, ocasionados de forma individual ou coletiva. Inicialmente, a principal maneira de se obter a solução de referidos conflitos foi por meio da autotutela (força). Tínhamos, então, a chamada "justiça do mais forte sobre o mais fraco". Mais tarde, por influência do direito romano, o Estado passou a solucionar tais conflitos por meio da jurisdição.

A jurisdição consiste em um poder-dever do Estado de quando provocado (Princípio da Inércia, art. $2^{\circ}$ do CPC) substituir a vontade das partes aplicando ao caso concreto a lei para obter a solução do conflito.

[...] uma das funções do Estado, mediante a qual este se substituiu aos titulares dos interesses em conflito para, imparcialmente, buscar a pacificação do conflito que os envolve, com a justiça. Essa pacificação é feita mediante a atuação da vontade do direito objetivo que rege o caso apresentando em concreto para ser solucionado; e o Estado desempenha essa função sempre mediante o processo, seja expressando 
imperativamente o preceito (através de uma sentença de mérito), seja realizando no mundo das coisas o que o preceito estabelece (através da execução forçada). (CINTRA; GRINOVER; DINAMARCO, 2013, p. 145)

Como os conflitos estão crescendo o Estado já não consegue mais solucioná-los nem oferecer a efetiva tutela aos direitos em tempo hábil, com isso temos hoje os chamados Meios Alternativos para a Solução dos Conflitos.

Estes meios alternativos consistem em formas de se obter a solução dos conflitos sem a participação do Estado (juiz), sendo a devida tutela dos direitos obtida pelas próprias partes ou mediante um terceiro que não o Estado.

Sendo assim o padrão seria a solução judicial do conflito realizada pelo Poder Judiciário e alternativa seriam as formas de solução não judiciais, ou seja, aquelas realizadas fora do Poder Judiciário. Então nesse sentido poderíamos identificar meios alternativos como meios extrajudiciais de solução de conflitos. Mas não é só nesse sentido que utiliza-se hoje em dia a expressão, essa 'alternativa' não é só à solução do conflito fora do Poder Judiciário mas também a solução realizada de outra forma mesmo que dentro do Poder Judiciário, ou em outras palavras, é alternativa também a solução do conflito que não se dá pela decisão final de mérito pelo juiz, mas por uma composição das partes dentro do próprio processo. Assim quando utilizamos a expressão meios alternativos de solução de litígios referimo-nos tanto a meios extrajudiciais como judiciais, porém este último só será um meio alternativo quando solucionar o conflito de forma compositiva sem a imposição da decisão judicial, ou como preferem alguns autores, de forma não-adversarial (MOURA, 2014).

Podemos citar como exemplos dessas formas alternativas de solucionar os conflitos a autocomposição (transação ou conciliação), mediação, arbitragem e as decisões dos tribunais administrativos.

Essas formas alternativas de solucionar os conflitos, em regra, conforme observa Theodoro (2007, p. 45), só podem ocorrer quando as partes forem maiores e capazes e o litígio versar sobre bens patrimoniais ou direitos disponíveis.

Dentre todos estes meios alternativos, atualmente, a conciliação vem sendo muito incentivada, uma vez que traz inúmeros benefícios para as partes.

Cumpre ressaltar que alguns autores entendem que a conciliação ou transação são formas para se obter a autocomposição, como, por exemplo, Theodoro Junior (2007, p. 45); outros, como Wambier e Talamini a consideram como uma espécie da qual o gênero é a autocomposição (2013, p. 101).

Independente da posição adotada, os efeitos práticos da sua aplicação 
serão os mesmos, pois a conciliação, como já mencionado, é uma técnica muito difundida e incentivada, que pode ocorrer judicialmente ou extrajudicialmente e consiste no fato de se obter a solução dos conflitos por meio de concessões mútuas dos próprios interessados (WAMBIER, 2013, p.101).

O Tribunal de Justiça do Estado do Paraná define a conciliação neste mesmo sentido:

A conciliação é a forma preferida de resolução de conflitos no nosso sistema processual porque ela é a melhor das duas: é mais rápida, mas barata, mais eficaz e pacifica muito mais. E nela não há risco de injustiça, na medida em que são as próprias partes que, mediadas e auxiliadas pelo juiz/conciliador, encontram a solução para o conflito de interesses. Nela não há perdedor. (TJ/PR)

Quando realizada judicialmente a conciliação pode ser obtida em qualquer fase do processo, sendo, inclusive, uma das funções do juiz tentar a sua realização conforme dispõe o artigo 125 do Código de Processo Civil. Quando obtida será homologada por sentença que extinguirá o processo com resolução de mérito nos termos dos artigos 269, III, e 449 do Código de Processo Civil.

A conciliação também pode ocorrer na via extrajudicial, o que teve início no Estado do Rio Grande do Sul, por meio dos Conselhos de Conciliação e Arbitramento, conforme nos ensina Marinoni e Arenhart (2013, p. 32):

A conciliação, realizada fora do processo do Estado e por juízes que não são seus agentes, foi inicialmente instituída na forma de "Conselhos de Conciliação e Arbitramento" (Rio Grande do Sul) e de "Juizados Informais de Conciliação" (São Paulo), e objetiva solucionar os conflitos de interesses sem dizer que "A" ou "B" tem razão, mas buscando conferir às partes condições favoráveis para a eliminação do conflito através de atos de sua própria vontade, ou melhor, buscando induzir as próprias partes a resolver seu caso.

Quando realizada extrajudicialmente, como nos processos administrativos ou pelas partes, com ou sem processo judicial, ela traz a rápida solução do litígio.

Se for realizada antes da existência de um processo judicial, além de trazer a rápida solução do conflito, como já mencionado, ela também evita o movimento do Poder Judiciário. Se realizada após o início do processo judicial ela pode a qualquer tempo ser trazida aos autos sendo submetida à homologação do juiz o que confere as partes maior credibilidade e segurança.

A Constituição Federal de 1.988 em seu artigo 98, inciso I, autorizou 
a criação dos juizados especiais, visando a agilizar a prestação jurisdicional. As Leis 9.099/95, 10.259/2011 e 12.153/2009 instituíram os Juizados Especiais Estadual, Federal e da Fazenda Pública, respectivamente. Este instituto tem como um de seus fundamentos a solução das controvérsias mediante conciliação (MENNA, 2009, p. 185).

A aplicação da conciliação aos casos práticos mostra-se, muitas vezes, a melhor opção, pois ambas as partes serão vencedores e vencidas, a solução do conflito ocorre de forma célere gerando um grande "desafogamento" no Poder Judiciário, que hoje possui um número excessivo de processos.

Ademais, cumpre ressaltar que o Projeto do Novo Código de Processo Civil estimula ainda mais a realização da conciliação. Esta ideia consta, inclusive, na exposição de motivos nos seguintes termos:

2) Pretendeu-se converter o processo em instrumento incluído no contexto social em que produzirá efeito o seu resultado. Deu-se ênfase à possibilidade de as partes porem fim ao conflito pela via da mediação ou da conciliação. 21 Entendeu-se que a satisfação efetiva das partes pode dar-se de modo mais intenso se a solução é por elas criada e não imposta pelo juiz.

Visando a dar efetividade a ideia acima exposta, o Novo Código de Processo Civil torna obrigatória a realização da audiência de conciliação, impondo a pena de ato atentatório à dignidade da justiça com aplicação da multa de até $2 \%$ do valor da causa ou da vantagem econômica objetivada para a parte que deixar de comparecer a esta audiência (artigo 333, § $5^{\circ}$ do Anteprojeto Novo Código de Processo Civil).

Dessa forma, percebe-se que hoje a conciliação é vista pelos juristas como uma das melhores formas para se solucionar os conflitos, motivo pelo qual deve ser aplicada nas causas que envolvem a Fazenda Pública sem restrições.

\section{FAZENDA PÚBLICA}

\subsection{Conceito}

Para se definir o que é a Fazenda Pública é necessário traçar algumas breves considerações acerca da Administração Pública.

A expressão Administração Pública, em seu sentido material, é utilizada para definir as atividades administrativas exercidas pelo Estado (União, Estados, Distrito Federal e Municípios), já em seu sentido formal é o conjunto de órgãos, pessoas e entidades que visam a atingir os objetivos do Estado (MARINELA, 2011, p. 87). 
Levando-se em consideração o sentido formal da Administração Pública, ou seja, a estruturação das pessoas jurídicas que desempenham as funções do Estado, chega-se a tradicional divisão da administração em direta e indireta, a primeira presta a atividade administrativa de forma centralizada po meio das pessoas políticas, ou seja, por meio da União, Estados, Distrito Federal e Municípios, já a segunda presta a atividade administrativa de forma descentralizada, por meio das Autarquias, Fundações Públicas, Sociedades de Economia Mista e Empresas Públicas (MARINELA, 2011, p.88).

A Administração Pública, tanto a direta como a indireta, é subdividida em centros especializados de competência que são os chamados Órgãos Públicos, e é neste contexto que encontramos a primeira definição de Fazenda Pública sendo esta considerada um órgão despersonalizado do Estado responsável pela gestão das finanças públicas, fixação e implementação das políticas econômicas, por isso é comum a utilização da expressão "Secretaria da Fazenda" ou "Ministério da Fazenda", para identificar o órgão responsável pela política econômica (CUNHA, 2012, p. 14 e 15).

No entanto, em um conceito mais lato a expressão Fazenda Pública significa a atuação do Estado em juízo, vejamos:

Na verdade a expressão Fazenda Pública representa a personificação do Estado, abrangendo as pessoas jurídicas de direito público. No processo em que haja a presença de uma pessoa jurídica de direito público, esta pode ser designada, genericamente de Fazenda Pública. A expressão Fazenda Pública é utilizada para designar as pessoas jurídicas de direito público que figurem em ações judiciais, mesmo que a demanda não verse sobre matéria estritamente fiscal ou financeira (CUNHA, 2012, p. 15).

Dessa forma, verificamos que quando a legislação processual utiliza o termo Fazenda Pública ela está se referindo a atuação da União, Estados, Distrito Federal, Municípios, Autarquias e Fundações Públicas em juízo.

Insta salientar que a expressão Fazenda Pública não se refere a atuação da Sociedade de Economia Mista e das Empresas Públicas em juízo, porque estas, diferentemente das Autarquias e Fundações Públicas, que são pessoas jurídicas de direito público, são pessoas jurídicas de direito privado (CUNHA, 2012).

Com isso, compreende-se os dois significados da expressão Fazenda Pública, o primeiro ligado as finanças públicas e o segundo relacionado a atuação do Estado em juízo, porém, ambos os conceitos estão interligados, uma vez que quando o Estado está em juízo uma possível condenação na demanda será arcada pelo seu erário (dinheiro público). 
A Administração Pública, quando ingressa em juízo por qualquer de suas entidades estatais, por suas autarquias, por suas fundações públicas ou por seus órgãos que tenham capacidade processual, recebe a designação tradicional de Fazenda Pública, porque é seu erário que suporta os encargos patrimoniais da demanda (MEIRELLES, 1998, p. 590).

Dessa forma, os conceitos se completam para possibilitar um maior entendimento acerca da atuação da Administração Pública tanto na esfera administrativa quanto na esfera judicial.

\subsection{Princípio da Indisponibilidade do Interesse Público}

A expressão interesse público está ligada a ideia de bem comum, de coletividade, de conjunto social. Definir exatamente o que significa interesse público não é fácil, no entanto Mello (2009, p. 59) o define como: "o interesse público deve ser conceituado como o interesse resultante do conjunto de interesses que os indivíduos pessoalmente têm quando considerados sem sua qualidade de membros da sociedade e pelo simples fato de o serem."

Ainda, conceituando interesse público destacamos:

O interesse público, pois, é um somatório de interesses individuais coincidentes em torno de um bem da vida que lhes significa um valor, proveito ou utilidade de ordem moral ou material, que cada pessoa deseja adquirir, conservar ou manter em sua própria esfera de valores. Esse interesse passa a ser público quando dele participam e compartilham um tal número de pessoas, componentes de uma comunidade determinada, que o mesmo passa a ser identificado como um querer valorativo predominante da comunidade. (BORGES, 2014, p.9)

Como esse interesse também é toda a sociedade ele é representado em juízo pela Fazenda Pública. Pietro (1991, p. 160), ainda, com a saliência de que "a Administração Pública não é titular do interesse público, mas apenas a sua guardiã; ela tem que zelar pela sua proteção".

Assim, levando em consideração a abrangência e a importância deste interesse, surgem dois grandes Princípios que são os alicerces de todo o Direito Público, quais sejam: Princípio da Supremacia do Interesse Público e Princípio da Indisponibilidade do Interesse Público.

O primeiro estabelece privilégios jurídicos à Administração e um patamar de superioridade do interesse público sobre o particular, assim a administração terá uma posição privilegiada em face dos administrados, bem como prer- 
rogativas e obrigações que não são extensíveis aos particulares (MARINELA, 2011, p. 27).

Já o segundo é expressamente previsto no artigo $2^{\circ}$, parágrafo único, inciso II, da Lei 9.784/99 e visa impedir abusos que eventualmente podem ocorrer em virtude da superioridade trazida pelo primeiro Princípio, exigindo que o administrador obedeça a várias formalidades (Lei), não podendo dispor livremente do interesse público.

Assim, o princípio da indisponibilidade serve para limitar a atuação do agente público, revelando-se um contrapeso à superioridade descrita no princípio da supremacia, podendo se afirmar que, em nome da supremacia do interesse público o Administrador pode muito, pode quase tudo, mas não pode abrir mão do interesse público (MARINELA, 2011, p. 28).

Dessa forma, percebe-se que a Administração não pode dispor do interesse público, devendo apenas zelar por ele, pois o administrador exerce sua atividade em nome do interesse da sociedade, devendo respeitar a vontade da Lei, e por isso não há autonomia em sua vontade nem liberdade irrestrita.

No entanto, cabe destacar que o Supremo Tribunal Federal vem atenuando a aplicação do Princípio da Indisponibilidade do Interesse Público:

Poder Público. Transação. Validade. Em regra, os bens e o interesse público são indisponíveis, porque pertencem à coletividade. É, por isso, o Administrador, mero gestor da coisa pública, não tem disponibilidade sobre os interesses confiados à sua guarda e realização. Todavia, há casos em que o princípio da indisponibilidade do interesse público deve ser atenuado, mormente quando se tem em vista que a solução adotada pela Administração é a que melhor atenderá à ultimação deste interesse. Assim, tendo o acórdão recorrido concluído pela não onerosidade do acordo celebrado, decidir de forma diversa implicaria o reexame da matéria fático-probatória, o que é vedado nesta instância recursal (Súm. 279/STF). Recurso extraordinário não conhecido. (RE 253885 / MG - MINAS GERAIS; Relator(a): Min. ELLEN GRACIE; Julgamento: 04/06/2002; Órgão Julgador: Primeira Turma; DJ 21-06-2002 PP-00118) (grifo nosso).

Dessa forma, resta evidente que a Fazenda Pública pode dispor de seus interesses quando restar comprovado ser esta a melhor opção para se atender referido interesse. 


\section{JUIZADO ESPECIAL DA FAZENDA PÚBLICA (LEI 12.153/2009)}

Quando temos a Fazenda Pública em juízo o direito em litígio envolve interesse público que, como já mencionado, é indisponível, por isso não é possível a realização da conciliação, pois esta consiste em concessões mútuas.

Visando a possibilitar uma justiça ágil e próxima do cidadão com a aplicação da conciliação nas causas envolvendo a Fazenda Pública foi criada a Lei n. 12.153/2009 (Lei do Juizado Especial da Fazenda Pública). Dessa forma, tornou-se possível a realização da conciliação mesmo se tratando de interesse indisponível.

Cumpre ressaltar que a referida lei visa a aplicação da conciliação no âmbito dos Estados, Distrito Federal, Municípios e suas respectivas autarquias e fundações públicas. No âmbito da União, suas autarquias e fundações a Lei 10.259/01, que instituiu o Juizado Especial Federal, em seu artigo 10, parágrafo único, já autorizava a realização da conciliação nos seguintes termos:

Art. 10. As partes poderão designar, por escrito, representantes para a causa, advogado ou não.

Parágrafo único. Os representantes judiciais da União, autarquias, fundações e empresas públicas federais, bem como os indicados na forma do caput, ficam autorizados a conciliar, transigir ou desistir, nos processos da competência dos Juizados Especiais Federais.

Dessa forma, a conciliação já vinha sendo realizada nas causas de até 60 salários mínimos no âmbito da Justiça Federal.

Insta salientar, também, que no Município de Palmas, Estado do Paraná, encontramos a Lei n. 1.790/2008, que antes mesmo da Lei dos Juizados da Fazenda Pública já autorizava a conciliação no âmbito civil para as causas de até quarenta salários mínimos, nos seguintes termos:

\section{LEI No 1790}

Súmula: "Autoriza o Poder Executivo Municipal a realizar acordos, conciliações e/ou transações cíveis".

A Câmara Municipal de Palmas, Estado do Paraná, nu uso das atribuições que lhe são conferidas por Lei, APROVOU e eu, Prefeito Municipal, SANCIONO a seguinte LEI

Art. $1^{\circ}$ - Autoriza o Poder Executivo Municipal a realizar acordos, conciliações e/ou transações cíveis.

Parágrafo Único: A presente autorização é extensiva aos casos extrajudiciais.

Art. $2^{\circ}$ - O Poder Executivo poderá efetuar acordos, conciliações e/ ou transações cíveis até o limite de 40 (quarenta) salários mínimos, 
vigentes na data de sua realização.

Art. $3^{\circ}$ - Esta Lei entra em vigor na data de sua publicação, com efeito retroativo a 15 de Dezembro de 2.007, revogando-se as disposições em sentido contrário.

Sala das Sessões do Poder Legislativo de Palmas, Estado do Paraná, em 30 de abril de 2008.

Cesar Pacheco Baptista

Presidente do Poder Legislativo Municipal

Com base no acima exposto, percebe-se que a Lei 12.135/09 veio apenas regulamentar a prática da conciliação nas causas envolvendo a Fazenda Pública.

Esta Lei traz dois requisitos para sua aplicação, um no artigo $2^{\circ}$ e outro no $\operatorname{artigo} 8^{\circ}$.

$\mathrm{O}$ artigo $2^{\circ}$ estabelece que serão de competência dos juizados especiais as causas que envolvem a Fazenda Pública até o valor de 60 salários mínimos, já o artigo $8^{\circ}$ estabelece a necessidade de elaboração de Lei pelo respectivo ente da Federação autorizando tal prática.

Esta exigência trazida pelo artigo $8^{\circ}$ vem em total consonância com o Princípio da Indisponibilidade do Interesse Público e da Legalidade, uma vez que a Administração deve obediência a Lei e é apenas a guardiã do interesse público.

Ademais, também, serve como um "porto seguro" para os procuradores do Estado, Distrito Federal e Municípios, uma vez que estes serão responsáveis por qualquer acordo realizado, podendo inclusive, em casos de dano ao erário, serem responsabilizados por Ato de Improbidade.

Por conseguinte, quando a Lei autorizar não há obstáculos para que se realize a conciliação, mesmo porque a conciliação, em muitos casos, é a melhor solução para a Fazenda Pública, pois resolve de forma mais célere os conflitos, bem como pode evitar condenações em valores consideráveis que, certamente, gerariam dano ao erário.

\section{BENEFÍCIOS DA APLICAÇÃO DA CONCILIAÇÃO A FAZENDA PÚ- BLICA}

A maior parte das demandas que existem hoje no judiciário são litígios que envolvem a Fazenda Pública, como já afirmado.

Segundo dados obtidos em uma pesquisa realizada pelo Conselho Nacional de Justiça (CNJ), "no âmbito estadual, a pesquisa mostra que os bancos e o setor público (municipal, estadual e federal) foram responsáveis por $34,4 \%$ dos processos novos que chegaram à primeira instância entre janeiro e outubro 
de 2011.” E "na Justiça Federal, o setor público federal e os bancos também apresentaram os maiores percentuais de processos novos, respectivamente com $68,8 \%$ e $13,4 \%$ na primeira instância e $92,3 \%$ e 7,2\% nos juizados especiais." (CNJ, 2014).

Com isso, percebe-se que as demandas que envolvem a Fazenda Pública expressam um grande número e, assim, há a necessidade de se agilizar a solução destes conflitos. Segundo o conselheiro José Guilherme Vasi Werner do $\mathrm{CNJ}$ "é uma tarefa do CNJ tentar discutir nacionalmente com as empresas que compõem o setor público e assim construir algum tipo de diálogo para evitarmos que esses processos continuem desaguando no Judiciário.” (CNJ, 2014)

Uma das formas para se tentar reduzir um pouco o número de processos em relação a Fazenda Pública seria a aplicação dos meios alternativos de solução dos conflitos, em especial da conciliação, tanto extrajudicial como judicial, pois sua aplicação traz benefícios para sociedade e para o próprio setor público.

Tais métodos, em especial a conciliação, a mediação e a arbitragem, possuem como vantagens, segundo alguns: possibilitar uma verdadeira composição da lide, de forma menos custosa, tanto emocional quanto financeiramente, e mais célere (WAMBIER; TALAMINI, 2013, p. 101).

O Ministro César Peluso ao iniciar oficialmente a Semana da Conciliação no Rio de Janeiro asseverou que se deve conscientizar os magistrados de que a prática da conciliação não é uma tarefa subalterna, secundaria nem extraordinária, mais sim tão importante quanto proferir sentenças (CNJ, 2014).

Dessa forma, ao se aplicar a conciliação extrajudicialmente, ou seja, no âmbito do processo administrativo ou realizada pelas partes fora do processo judicial, além das vantagens acima citadas, ela evita a propositura de uma ação judicial.

Já no âmbito judicial com a criação da Lei dos Juizados tornou-se um pouco mais fácil a realização da conciliação nas causas envolvendo a Fazenda Pública, no entanto como a demanda é gigantesca o ideal seria a aplicação da conciliação em todas as causas que envolvem o setor público, mediante autorização legal para o fiel cumprimento do Princípio da Legalidade.

Um dos grandes benefícios da aplicação da conciliação judicial seria que a solução do conflito viria da vontade das partes e não seria outorgada pelo Estado, pelo que administração e administrado chegariam a melhor solução atendendo o interesse de ambos. Também, os conflitos seriam solucionados de forma mais célere, o que além de satisfazer as partes desafogaria o Poder Judiciário.

Os benefícios da prática da conciliação são significativos tanto no âmbito social quanto no econômico. 
Visando a obter a solução do maior número de conflitos por meio da conciliação o CNJ institui a Campanha "Conciliar é Legal".

Tal campanha vem obtendo ótimos resultados e como exemplo pode-se citar o balanço do Mutirão da Conciliação ocorrido no Estado do Paraná em 2009 (Fórum Cível de Curitiba) a pedido do Banco Itaú, o qual 77,77\% dos processos foram resolvidos amigavelmente (CNJ, 2014).

Com relação a Fazenda Pública verifica-se, ainda, que ao aplicar a conciliação em suas demandas se estará respeitando, bem como cumprindo os Princípios da Indisponibilidade do Interesse Público, da legalidade, da Economia Processual e da Celeridade.

O Princípio da Indisponibilidade (já conceituado) estará sendo cumprido na medida em que ao se buscar a conciliação o procurador do ente público buscará a proposta que melhor alcance o interesse público, até porque em casos de má-fé e fraude, que causem dano ao erário, ele poderá ser responsabilizado por Improbidade Administrativa.

O Princípio da Legalidade, previsto nos artigos $5^{\circ}$, inciso II e 37, caput, da Constituição Federal, é a base de todo o Estado Democrático de Direito. Para o direito público este princípio determina que a administração pública pode fazer somente o que a lei autorizar ou determinar, tento em vista que o interesse em questão é da sociedade, da coletividade (MARINELA, 2011, p. 30).

Neste contexto, o princípio acima é respeitado, bem como cumprido, uma vez que para realizar a conciliação no âmbito dos juizados especiais há a determinação da criação da lei pelo respectivo ente federativo.

Os Princípios da Economia Processual e da Celeridade podem ser estudados em conjunto, pois seus conceitos se completam para definir que o processo deve ser rápido e efetivo. Neste sentido:

É evidente que sem efetividade, no que concerne ao resultado processual cotejado com o direito material ofendido, não se pode pensar em processo justo. E não sendo rápida a resposta do juízo para a pacificação do litígio, a tutela não se revela efetiva. Ainda que afinal se reconheça e proteja o direito violado, o longo tempo em que o titular, no aguardo do provimento judicial, permaneceu privado de seu bem jurídico, sem razão plausível, somente pode ser visto como uma grande injustiça. Daí porque, sem necessidade de maiores explicações, se compreende que o Estado não pode deixar de combater a morosidade judicial e que, realmente, é um dever primário e fundamental assegurar a todos quantos dependam da tutela da Justiça uma duração razoável para o processo e um empenho efetivo para garantir a celeridade da respectiva tramitação (THEODORO, 2007, p. 36). 
Assim, ao se aplicar a conciliação tem-se a solução do conflito de forma rápida e efetiva, pois a solução e obtida por meio da vontade das partes e em um tempo razoável.

\section{CONSIDERAÇÕES FINAIS}

Como a Fazenda Pública é hoje uma das maiores litigantes do Poder Judiciário há a necessidade de se resolver estes processos de forma rápida e efetiva para as partes, bem como de desafogar o judiciário para que melhor possa atender a sociedade.

Neste contexto, a aplicação dos meios alternativos de solução de conflitos, especialmente a conciliação possui extrema relevância. Sabe-se que para aplicar esses meios é recomendável que as partes envolvidas no litígio sejam maiores e capazes e a controvérsia diga respeito a direito disponível, assim encontramos, de imediato, uma barreira para a aplicação da conciliação a Fazenda Pública.

No entanto, a técnica da conciliação vem sendo muito difundida e incentivada. Comprovando tal fato tivemos em 2009 a criação dos Juizados Especiais da Fazenda Pública, o qual autorizou a prática da conciliação nas causas de até 60 salários mínimos e desde que haja lei do respectivo ente federativo autorizando tal prática.

Certamente a autorização trazida pela lei dos Juizados da Fazenda Pública trará muitos benefícios ao setor público, a parte contraria e ao Poder Judiciário. Porém, como a demanda é grande, o ideal seria aplicarmos a conciliação em todas as causas em que a Fazenda Pública for parte.

Neste ponto, destaca-se o posicionamento do Supremo Tribunal Federal que considerou possível a amenização do Princípio da Indisponibilidade do Interesse Público para se alcançar a solução que melhor atenda ao interesse da coletividade.

Dessa forma, percebe-se que é possível a aplicação da conciliação nas causas em que a Fazenda Pública for parte, pois sua aplicação é benéfica uma vez que o conflito será resolvido pelas próprias partes que, certamente, sairão satisfeitas. A solução será obtida de forma rápida; se ocorrer na via administrativa evitará uma ação judicial; se for judicial também irá reduzir o número de processos uma vez que o resultado será alcançado rapidamente.

Ademais, a aplicação da conciliação a Fazenda Pública respeita o Princípio base do Direito de forma geral, qual seja, o Princípio da Legalidade, bem como o Princípio base do Direito Público, qual seja, o da Indisponibilidade do Interesse Público, além de respeitar e cumprir os Princípios da Celeridade e da Economia Processual. 
Desta maneira, como os percentuais trazidos pela pesquisa realizada pelo Conselho Nacional de Justiça demonstram que a Fazenda Pública é hoje a maior litigando do Poder Judiciário, bem como que a prática da conciliação vem obtendo ótimos resultados na solução dos conflitos, nada mais certo do que se aplicar a conciliação nas causas que a envolvem, para se obter, de forma célere e efetiva, a solução destes conflitos.

\section{REFERÊNCIAS}

BORGES, A. G. Supremacia do interesse público: desconstrução ou reconstrução?. Revista Diálogo Jurídico. Disponível em: <http:// marinela.ma/i/f/supremacia $\% 20$ do $\% 20$ interesse $\% 20$ p $\%$ C3\%BAblico. $\% 20$ descontru\%C3\%A7\%C3\%A30\%20ou\%20constru\%C3\%A7\%C3\%A3o.pdf>. Acesso em: 06 jan. 2014.

BRASIL. Código de processo civil. 5. ed. São Paulo: Revista dos Tribunais, 2010 .

. Conselho Nacional de Justiça. Órgãos federais e estaduais lideram 100 maiores litigantes da justiça. Disponível em: <http://www.cnj.jus.br/ noticias/cnj/21877-orgaos-federais-e-estaduais-lideram-100-maiores-litigantesda-justica>. Acesso em: 19 jan. 2014a.

. Conselho Nacional de Justiça. Ministro Peluso ressalta resultados sociais e econômicos da conciliação. Disponível em: $<$ http://www.cnj.jus.br/ noticias/cnj/17217-ministro-peluso-abre-semana-e-ressalta-importancia-daconciliacao>. Acesso em: 19 jan. 2014 b.

. Conselho Nacional de Justiça. Mutirão por conciliação no PR fecha acordos em 77\% dos casos. Disponível em: $<$ http://www.cnj.jus.br/noticiasgerais/7024-mutirao-por-conciliacao-no-pr-fecha-acordos-em-77-dos-casos>. Acesso em: 19 jan. 2014c.

Constituição Federal. 5. ed. São Paulo: Revista dos Tribunais, 2010.

Lei 9.784 de 29 de janeiro de 1999. Disponível em: <http://www.

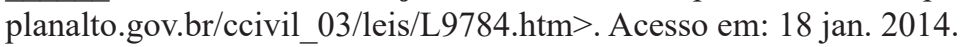

. Exposição de motivos do projeto do novo código civil. Disponível em: $<$ http://www.senado.gov.br/senado/novocpc/pdf/anteprojeto.pdf $>$. Acesso em: 18 jan. 2014. 
. Superior Tribunal de Justiça. REsp 253885/ MG. Relator:

Ministro Ellen Gracie, 1a Turma, Brasília, DF, 04 de junho de 2002, DJ 21.06.2002. Disponível em: <http://www.stf.jus.br/portal/jurisprudencia/ listarJurisprudencia.asp? $1=\% 28$ interesse + adj $+\mathrm{p} \%$ FAblico + adj3+atenuado $\%$ $29 \&$ base $=$ baseAcordaos\&url=http://tinyurl.com/mtlh6xl>. Acesso em: 07 jan . 2014.

CANABARRO, L. E. C. Mediação como método de solução alternativa de conflito. Serie Aperfeiçoamento de Magistrados. Disponível em: <http:// www.emerj.tjrj.jus.br/serieaperfeicoamentodemagistrados/paginas/series/8/ judicializacaodasaudeII_88.pdf $>$. Acesso em: 18 jan. 2014.

CINTRA, A. C. de A.; GRINOVER, A. P.; DINAMARCO, C. R. Teoria geral do processo. 23. ed. São Paulo: Malheiros, 2013.

CUNHA, L. C. da. A fazenda pública em juízo. 10. ed. São Paulo: Dialética, 2012.

DI PIETRO, M. S. Z. Discricionariedade administrativa na Constituição de 1988. São Paulo: Atlas, 1991.

HUMBERTO, T. J. Curso de direito processual civil. 47. ed. Rio de Janeiro: Forense, 2007. v. 1.

MARINELA, F. Direito administrativo. 5. ed. Niterói: Impetus, 2011.

MARINONI, L. G.; ARENHART, S. C. Processo de conhecimento. 11. ed. São Paulo: Revista dos Tribunais, 2013. v. 2.

MEIRELLES, H. L. Direito administrativo brasileiro. 23. ed. São Paulo: Malheiros, 1998.

MELLO, C. A. B. de. Curso de direito administrativo. 26. ed. São Paulo: Malheiros, 2009.

MENNA, F. de V. Processo civil. 8. ed. São Paulo: Revista dos Tribunais, 2009.

MOURA, R. H. P. Meios alternativos de solução dos litígios. Disponível em: $<$ http://mediacaoeadvocacia.com.br/artigos-juridicos/meios-alternativos-desolucao-de-litigios-62>. Acesso em: 18 jan. 2014. 
PALMAS. Lei 1790 de 2008. Disponível em: <http://www.camarapalmas. pr.gov.br/lei/leitor.php. Acesso em: 06 jan. 2014.

PARANÁ. Tribunal de Justiça do Estado do Paraná. Centro Judiciário de Solução de Conflitos e Cidadania. Disponível em: $<$ http://www.tjpr.jus.br/ conciliacao>. Acesso em: 18 jan. 2014.

RIBEIRO, F. W. M. O projeto do novo código de processo civil favorece a conciliação? Jus Navigandi, Teresina, a. 18, n. 3744, 1 out. 2013. Disponível em: $<$ http://jus.com.br/artigos/25431/o-projeto-do-novo-codigo-de-processocivil-favorece-a-conciliacao>. Acesso em: 18 jan. 2014.

VOLPI, E. K. R. Conciliação na Justiça Federal: a indisponibilidade do interesse público e a questão da isonomia. Disponível em: $<$ http://www.pgfn. fazenda.gov.br/revista-pgfn/ano-i-numero-ii-2011/012.pdf>. Acesso em: 06 jan. 2014.

WAMBIER, L. R.; TALAMINI, E. Curso avançado de processo civil. 13. ed. São Paulo: Revista dos Tribunais, 2013. v.1.

\section{THE BENEFITS OF APPLYING PUBLIC TREASURY CONCILIATION}

ABSTRACT: The present study, through surveys performed by the National Council of Justice, shows that currently, the Public Treasury is one of the biggest litigants of the Judiciary and, by seeking to reduce these processes swiftly and effectively, listing what would be the benefits to the parties of applying conciliation on these causes. Thus, it presents an analysis of alternative means for resolving conflicts, especially conciliation, emphasizing the key aspects of Public Administration to be able to understand the concept of Public Treasury. Finally, it verifies that the application of conciliation is beneficial to all parties, respecting the Principle of Unavailability of Public Interest, since this Principle, according to the Supreme Federal Court, can have its application ameliorated, although being considered as one of the pillars of the entire administrative law, as well as respecting and enforcing the Principles of Legality, Celerity and Process Economy.

KEYWORDS: Public Treasury; Conciliation; Public Interest. 


\section{LOS BENEFICIOS DE LA APLICACIÓN DE CONCILIACIÓN JUNTO A LA HACIENDA PÚBLICA}

RESUMEN: El estudio demuestra delante investigaciones realizadas por el Consejo Nacional de Justicia que, actualmente, la Hacienda Pública es una de la mayores litigantes del Poder Judiciario y en búsqueda de reducir estos procesos de forma célere y eficaz para las partes, enumera cuales serían los beneficios de la aplicación de conciliación en estas causas. Así, presenta un análisis de los medios alternativos de solución de conflictos, especialmente de conciliación, destacando, enseguida, los principales aspectos de la Administración Pública para poder comprender el concepto de Hacienda Pública. Por fin, se verifica que la aplicación de conciliación es benéfica para todas las partes, que respeta el Principio de la Indisponibilidad del Interés Público, pues, segundo el Supremo Tribunal Federal, este Principio, aunque sea considerado uno de los pilares de todo derecho administrativo, puede tener su aplicación amenizada, así como los Principios de Legalidad, Celeridad y Economía Procesal son también respetados y cumplidos.

PALABRAS CLAVE: Hacienda Pública; Conciliación; Interés Público. 


\section{Arquivos de Ciências Empresariais da Unipar}

ISSN 1517-6304

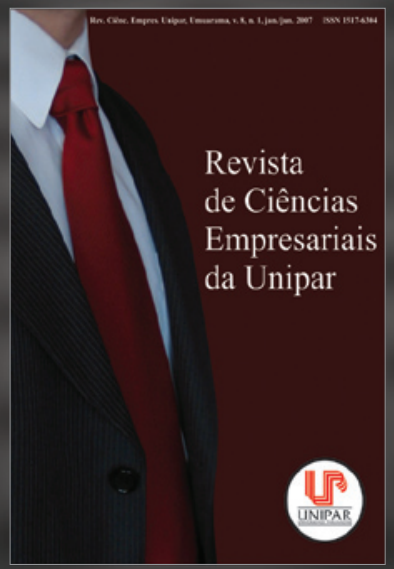

- Publica trabalhos referentes às áreas de Ciências Contábeis, Administração e Economia.

- Periodicidade: Semestral

- e-mail: rcempresariais@unipar.br http://revistas.unipar.br/empresarial

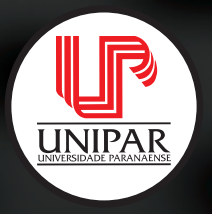

